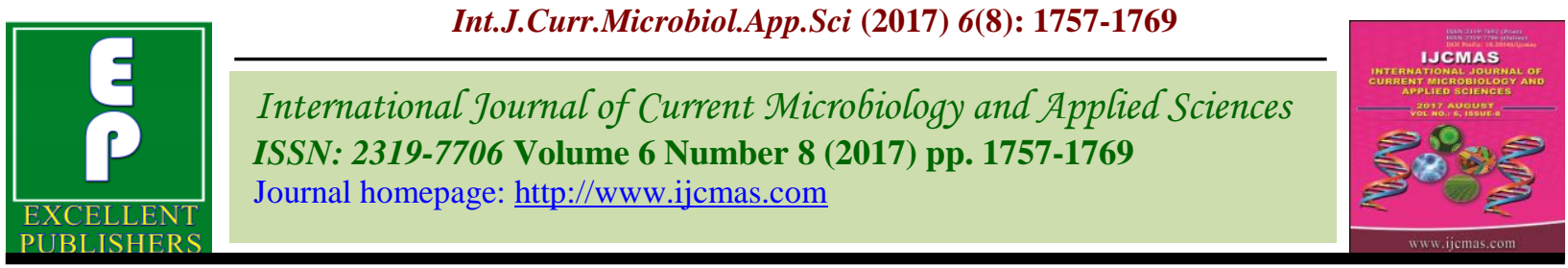

Original Research Article https://doi.org/10.20546/ijcmas.2017.608.208

\title{
In vitro Compatibility Study between the Rhizobium and Native Trichoderma Isolates from Lentil Rhizospheric Soil
}

\author{
Tanusree Das*, Sunita Mahapatra and Srikanta Das \\ Department of Plant Pathology, Bidhan Chandra Krishi Viswavidyalaya, \\ Mohanpur, Nadia, West Bengal, India \\ *Corresponding author
}

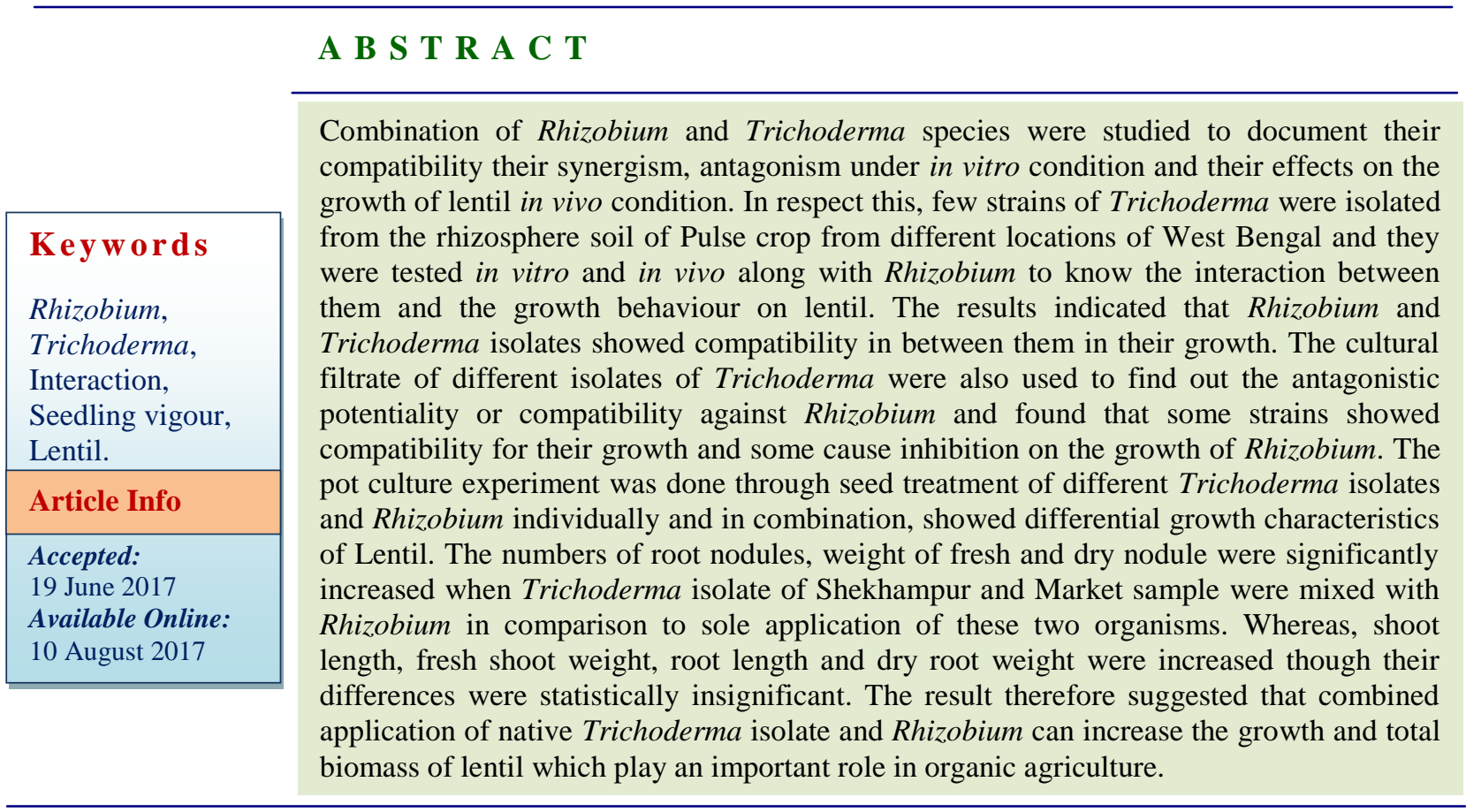

\section{Introduction}

Lentil (Lens culinaris) is an edible pulse, commonly used for human nutrition, animal feed and soil fertility (Sarker and Kumar, 2011). Its cultivation enriches soil nutrient status by adding nitrogen, carbon and organic matter which promotes sustainable cerealbased systems of crop production (Frederick et al., 2006; Badarneh, 1995; O' Hara et al., 2002; Schulze et al., 2006). Combined or simulation application of rhizobacteria with other bio-inoculants and pesticides are not always compatible and synergistic or additive
(Medina-Martinez et al., 2002). The inoculation of seeds with Rhizobium is known to increase nodulation, nitrogen uptake, and growth and yield response of crop plants (Dorosinsky and Kadyrov, 1975; Patil and Shinde, 1980; Herandez and Hill, 1983; Rudresh et al., 2005). The beneficial effect of Rhizobium sp. has been a main focus in terms of biological nitrogen fixation in the recent past (Deshwal et al., 2003). Trichoderma have long been known as effective antagonists against soil borne plant 
pathogenic fungi, nematodes (Rifai, 1969, Papavizas, 1985; Mukhopadhay et al.,1986; Chet, 1987; Bennett and Lane, 1992; Kumar and Mukherji, 1996, Rudresh et al., Sivan et al., 1984; Coley- Smith et al., 1991) and consider as a plant growth enhancer and plant defence inducer (Verma et al., 2007). It is encouraging that the application of Trichoderma spp. with other biofertilizer is now also getting importance for enhancing nutrition and suppressing soil borne plant pathogens (Rudresh et al., 2005; Whipps and Lumsden, 2001). There is no doubt that both this two are highly potential genus with several of its species having antagonistic potential. So, attention needs to be given towards this bio-control agent. So, the study on the interaction of rhizobacteria with other bio-inoculants and their effects on PGPR both in vitro and in vivo need to be done to judge their compatibility with other bio-inoculants. The study of combining these two organisms is of great potential value to organic agriculture in order to avoid fertilizers and pesticides. In the present investigation two groups of microorganisms viz., Rhizobium and Trichoderma spp. were studied to document both their compatibility and their combined effects on the growth and yield of lentil both in vitro and in vivo conditions. In respect this, few strains of Trichoderma were isolated from different lentil rhizosphere of West Bengal and they were then tested in vitro and in vivo along with Rhizobium to know the interaction between them and their on the enhancement the seedling vigour of Lentil.

\section{Materials and Methods}

\section{Collection of soil samples}

Soils were collected from different locations of Nadia district, West Bengal. Samples were collected from lentil rhizosphere. The location from where the samples were collected was far away from one another so as to represent an eco-distribution pattern of Trichoderma habitation of West Bengal. Sl. No. Isolation code Village/Sample

MSTh1 Marketed Sample

HTh2 Hoogly

ShTh3 Shekhampur

RaTh4 Ranaghat

ChTh5 Chakdah

KaTh6 Kakdwip

The Rhizobium was collected from the Survey selection and Mass production, BCKV.

\section{Isolation technique}

Trichoderma were isolated from the soil of the Lentil rhizosphere (Harris and Sommers, 1968) using TSM (Elad and Chet, 1983). The soils were collected from rhizosphere of different locations of WB and dried under shade and ground to powder with a mortar and pestle and passed through $2 \mathrm{~mm}$ mesh sieve, $10 \mathrm{gm}$ of powdered soil was mixed with $90 \mathrm{ml}$ of sterile distilled water to prepare mother suspension. This suspension was used for serial dilution continued up to 10-2 to 10$7.1 \mathrm{ml}$ of the suspension from each of 10-6 and 10-7 dilution was placed on $20 \mathrm{ml}$ of TSM in each of the sterilized petriplates by giving a gentle whirling motion to the plate and allowed them to incubate in $28\left( \pm 1^{\circ} \mathrm{C}\right)$ temperature (Islam et al., 2005) for seven days. 3 replications were maintained for each dilution for a particular soil.

The green colonies of the bio antagonists usually appeared at the 4th and 5th day of incubation. Each colony was studied carefully under microscope using $0.1 \%$ lactophenol cotton blue stain $(0.1 \mathrm{gm}$ cotton blue mixed in $100 \mathrm{ml}$ of lactophenol solution) and compared to the monographs of Trichoderma (Rifai, 1969) for identification at genus and species level. The separated colonies were then 
transferred to PDA slants by using single hyphal tip method (Rangaswami, 1958). The slants were maintained at $5^{\circ} \mathrm{C}$ for further use.

\section{Maintenance of rhizobacterial isolates}

The individual bacterial colony was picked up and streaked on Yeast extract manitol agar (YEMA) and after incubation at $28^{\circ} \mathrm{C}\left( \pm 1^{\circ} \mathrm{C}\right)$, kept at $4^{\circ} \mathrm{C}$ for short period maintenance. Periodic (at 15 days intervals) sub culturing was done on the same medium.

Compatibility study between the Trichoderma isolates and Rhizobium (In vitro)

\section{Dual culture method}

The Tricoderma isolates were plated with Rhizobium to evaluate their interaction by dual culture technique as described by Morton and Strouble (1955). A 5mm diameter mycelia disc from the margin of the 7 days old culture of Trichoderma isolates was placed at the one end of the plate one $\mathrm{cm}$ away from the periphery and $108 \mathrm{cfu} / \mathrm{ml}$ suspension of Rhizobium was streaked at the other periphery.

The experiment was setup in completely randomised design with 3 replications for each treatment. In control only Trichoderma discs were placed. Inoculate plates were incubated at $280 \mathrm{C}\left( \pm 1^{\circ} \mathrm{C}\right)$ for 7 days. 2-3 days after the incubation period, radial growth of Trichoderma isolates was measured and per cent inhibition of average radial growth was calculated in relation to mycelia growth of the control (Vincent, 1947).

$\mathrm{I}=\mathrm{x} 100$

$\mathrm{I}=\%$ Inhibition of growth

$\mathrm{C}=$ mycelial growth in control plate

$\mathrm{T}=$ mycelial growth in test plate

\section{Culture filtrate method}

Trichoderma harzianum was inoculated to flasks containing sterilized Czapeck's broth with 0.1 per cent yeast extract and incubated for 12 days and the contents were filtered and passed through membrane filter. The filtrate was incorporated into Yeast extract manitol broth at $20 \%(\mathrm{VN})$ and inoculated with $0.5 \mathrm{ml}$ of Rhizobium cell suspension (3x $10^{7}$ $\mathrm{CFU} / \mathrm{ml}$ ) and incubated on a rotary shaker for 72 at $28^{\circ} \mathrm{C}\left( \pm 1^{\circ} \mathrm{C}\right)$. At the end of incubation the population of Rhizobium was estimated (Jayaraj and Ramabadran, 1999).

Evaluation of growth interaction of Rhizobium and Trichoderma in vitro (by colorimeter)

Four strains of Trichoderma were grown with Rhizobium species in YEMB to study the growth pattern of both. $50 \mathrm{ml}$ of Yeast Extract Manitol broth was sterilized and inoculated with $0.5 \mathrm{ml}$ of spore suspension $\left(3 \times 10^{7}\right.$ spores $/ \mathrm{ml}$ ) and $0.5 \mathrm{ml}$ of the cell suspension of Rhizobium $\left(3 \times 10^{7} \quad \mathrm{CFU} / \mathrm{ml}\right)$. Both Trichoderma and Rhizobium was grown individually in YEMB in different flasks for comparison. The flasks were continuously shaken in an orbital shaker for $72 \mathrm{~h}$ at $28^{\circ} \mathrm{C}$ $\left( \pm 1^{\circ} \mathrm{C}\right)$ in $100 \mathrm{rpm}$ after which the intensity of growth was assessed by observing the optical density of the medium in a colorimeter at 530 nm (Jayaraj and Ramabadran, 1999). To count the population of Trichoderma, Rhizobium individually and in combination serial dilution and plating method using specific medium were followed.

Evaluation of interaction between selected Trichoderma isolates with Rhizobium (in vivo)

Lentil seeds (Var. B-177) were tested for germination percentage by wet blotter technique to ascertain that it is free from any 
diseases (De Tempe and Binnerts, 1979) fifty seeds were arranged at equal distance on a wet blotter placed in a petriplate and incubated at room temperature for three days. The numbers of germinated seeds out of total number of seeds observed were recorded along with pathogen infestations, if any. After testing the lot for germination percentage and seed health, Lentil seeds (B- 177) were soaked in water for 24 hours (one day before the experiment). The seeds were surface sterilized with $\mathrm{HgCl}_{2}$ and treated with the following organisms: (a) Trichoderma spp. spore suspension (1-3 x $10^{8}$ spores/ml) @ $3 \mathrm{ml} / 10 \mathrm{gm}$ of seed; (b) Rhizobium cell suspension (1-3 x 10 8 CFU/ml) @ $3 \mathrm{ml} / 20 \mathrm{~g}$ of seed; (c) Trichoderma + Rhizobium at the above level and (d) control seeds surface sterilized $0.2 \% \mathrm{HgCI}_{2}$ with treating them with Rhizobium and Trichoderma individually.

The seeds (6 Nos.) were sown in earthen pots $(10 \times 15 \mathrm{~cm})$ filled with unsterilized soil. Regular watering and observations were made during the development of the plants. The plants were removed after 30 days from each pot and the root zone was washed under running tap. The pinkish nodules were counted and the other observations were recorded (Jayaraj and Ramabadran, 1999).

\section{Results and Discussion}

Evaluation of antagonistic potential of selected Trichoderma isolate against Rhizobium

Different Trichoderma spp. were isolated, one from Market sample (MSTh1) and rest 5 from different places of West Bengal like Hoogly (HTh2), Shekhampur (ShTh3), Ranaghat (RaTh4), Chakdah (ChTh5), Kakdwip (KaTh6) from the root rhizosphere of different pulse crops. These Trichoderma isolates were grown with the Rhizobium collected from the surface selection, mass production, $\mathrm{BCKV}$, to know the antagonistic potential or compatibility against the Rhizobium in vitro condition. The dual culture plating was done and observations were recorded at 2 days interval after the date of inoculation. It was observed that in every date of observation the growth of the Trichoderma was different and increased significantly with the increase age of the culture. Among the different isolates of Trichoderma Market sample (MSTh1) produced profused growth along with Rhizobium and significantly at par with individual growth of this Market sample of Trichoderma (untreated control) $(7.60 \mathrm{~cm}$ ) which cover the full plate after 9 days of inoculation (Table 1 and Fig. 1).

It was also observed that, the Shekhampur isolate of Trichoderma (ShTh3), and Ranaghat isolate of Trichoderma (RaTh4) were also significantly at par with each other and also grow profusely $(7.53 \mathrm{~cm}$ and 7.50 $\mathrm{cm}$ respectively), whereas minimum growth were observed from Hoogly of Trichoderma (HTh2) at 9 days after inoculation which is $5.93 \mathrm{~cm}$. According to their growth over Rhizobium, Market sample of Trichoderma (MSTh1) produced maximum followed by Trichoderma isolated from Shekhampur (ShTh3) i.e. $5.23 \mathrm{~cm}$ and minimum in Hoogly $(\mathrm{HTh} 2)$ isolate $4.33 \mathrm{~cm}$ irrespective of their age of growth. According to their growth against Rhizobium, (Plate: 3) Ranaghat (RaTh4), Chakdah (ChTh5) and Kakdwip (KaTh6) were similar $(4.68,4.46$, and $4.47 \mathrm{~cm}$ respectively) (Table 4).

The in vitro study of different Trichoderma isolates and Rhizobium in dual culture plate technique showed Market sample of Trichoderma produced profuse growth along with Rhizobium and minimum by Hoogly isolate. It indicated that Rhizobium and Trichoderma isolates showed a compatible reaction in growth and it was suggested by Jayaraj and Ramanadran (1999). 
Influence of cultural filtrate of Trichoderma spp. on the growth of Rhizobium and vice versa

Influence of Rhizobium on the mycelia growth of Trichoderma

Different cultural filtrate of different isolates of Trichoderma also used to find out the antagonistic potentiality or compatibility against Rhizobium up to 240 hours after inoculation. Every 48 hours after inoculation the result showed that the growth of Trichoderma were increased significantly and maximum was observed after 240 hours of inoculation $(6.905 \mathrm{~cm})$. Though, the interaction between the Trichoderma isolates and the age of the colony was not statistically significant. Here, Shekhampur (ShTh3), Ranaghat (RaTh4), and Chakdah (ChTh5) isolate of Trichoderma showed no significant difference among themselves in increase the growth of colony diameter $(4.87,4.93$. and $4.72 \mathrm{~cm}$ respectively) whereas maximum as noticed on Market sample isolate (MSTh1) $5.267 \mathrm{~cm}$ and minimum is Kakdwip isolate (KaTh6) $3.517 \mathrm{~cm}$ (Tables 2 and 5).

\section{Influence of Trichoderma filtrate on} Rhizobium population

Rhizobium was inoculated on 6 different culture filtrate of Trichoderma and it was observed that increase in the age if inoculation there is significant increase in Rhizobium population irrespective of different Trichoderma isolates.

Though within the cultural filtrate of different Trichoderma isolates, the growth of Rhizobium were reduced significantly in comparison to untreated control (only Rhizobium isolate), no Trichoderma inoculation, except Chakdah isolate of Trichoderma (ChTh5) where the Rhizobium colony was highest (119.67) statistically at par with untreated control Rhizobium without Trichoderma filtrate (124.60) irrespective of date of observations (Fig. 1). It was also observed that the Rhizobium growth was statistically insignificant when they are inoculated on cultural filtrate of Trichoderma Hoogly isolate (163 nos.), Ranaghat isolate (161.67), and Kakdwip isolate (168.33) on last date of observation. In every date of observation the colony growth of Rhizobium on cultural filtrate of Chakdah isolate of Trichoderma (ChTh5) was statistically at par with each other, whereas, minimum Rhizobium growth (colony count) was noticed when the Rhizobium grow on the cultural filtrate of Market sample of Trichoderma in every date of observation statistically at par with Hoogly isolate of Trichoderma (Table $3)$. The results therefore indicate that, except Chakdah isolate of Trichoderma, other cultural filtrates of Trichoderma showed some inhibitory effect on the growth of Rhizobium (Table 5).

When the cultural filtrate of Trichoderma was in corporate into the YEMA and inoculated with Rhizobium cell suspension, it was observed that all the cultural filtrate showed some inhibitory effect on the growth of Rhizobium except Chakdah isolate of Trichoderma which was similar to that of the result Sethi and Subha Rao (1968) that growth of Rhizobium showed slight inhibitory effect on the certain strains of Trichoderma. Similarly, the growth of different strain was increased significantly without the effect of Rhizobium. It indicated that growth of Trichoderma showed no inhibition when they incorporated with Rhizobium.

Intensity of growth of different isolates of Trichoderma with Rhizobium and its OD Value

The results showed that OD value of different Trichoderma isolates over Rhizobium was 
different and their differences were statistically significant. Maximum OD value was observed on Market sample of Trichoderma over Rhizobium (0.590) followed by Ranaghat isolate over Rhizobium (0.513) and Hooghly isolate of Trichoderma (0.510). Though, their differences were statistically significant except later two treatments and minimum in Shekhampur isolate of Trichoderma over Rhizobium (0.280).

Growth of Rhizobium and their OD value within the different Trichoderma isolates were statistically significant. Maximum Rhizobium growth was increased over Shekhampur isolate $(51.28 \%)$ followed by the growth of Rhizobium on Ranaghat and Hoogly isolates of Trichoderma (21.02\% and $21.53 \%$ respectively) and minimum within the market sample of Trichoderma (9.23). though the OD value of Rhizobium was statistically at par with Ranaghat and Hoogly isolates of Trichoderma.

Growth of different isolates of Trichoderma over Rhizobium were decreased significantly and maximum growth reduction of OD value was observed on Ranaghat isolate (-49.60) and minimum in market sample of Trichoderma (-21.19) followed by Shekhampur isolate (-22.18) and Hoogly isolate (-26.95) though later 3 Trichoderma isolates showed no significant differences in reduction of OD value within the Rhizobium over control growth of Trichoderma. The population of Rhizobium in control condition and their OD value showed no significant differences within themselves.

Similarly the growth of Trichoderma, the growth of Rhizobium within different Trichoderma isolates showed no significant differences among themselves over the untreated control of Rhizobium. The population of different isolates of Trichoderma was statistically significant and maximum population was observed in Market sample of Trichoderma (5.66) statistically at par with Shekhampur isolates of Trichoderma (5.33) and minimum in Ranaghat isolate of Trichoderma (2.33) statistically at par with Hoogly isolate (2.66).

Table.1 In vitro antagonistic potential of Trichoderma isolates against Rhizobium

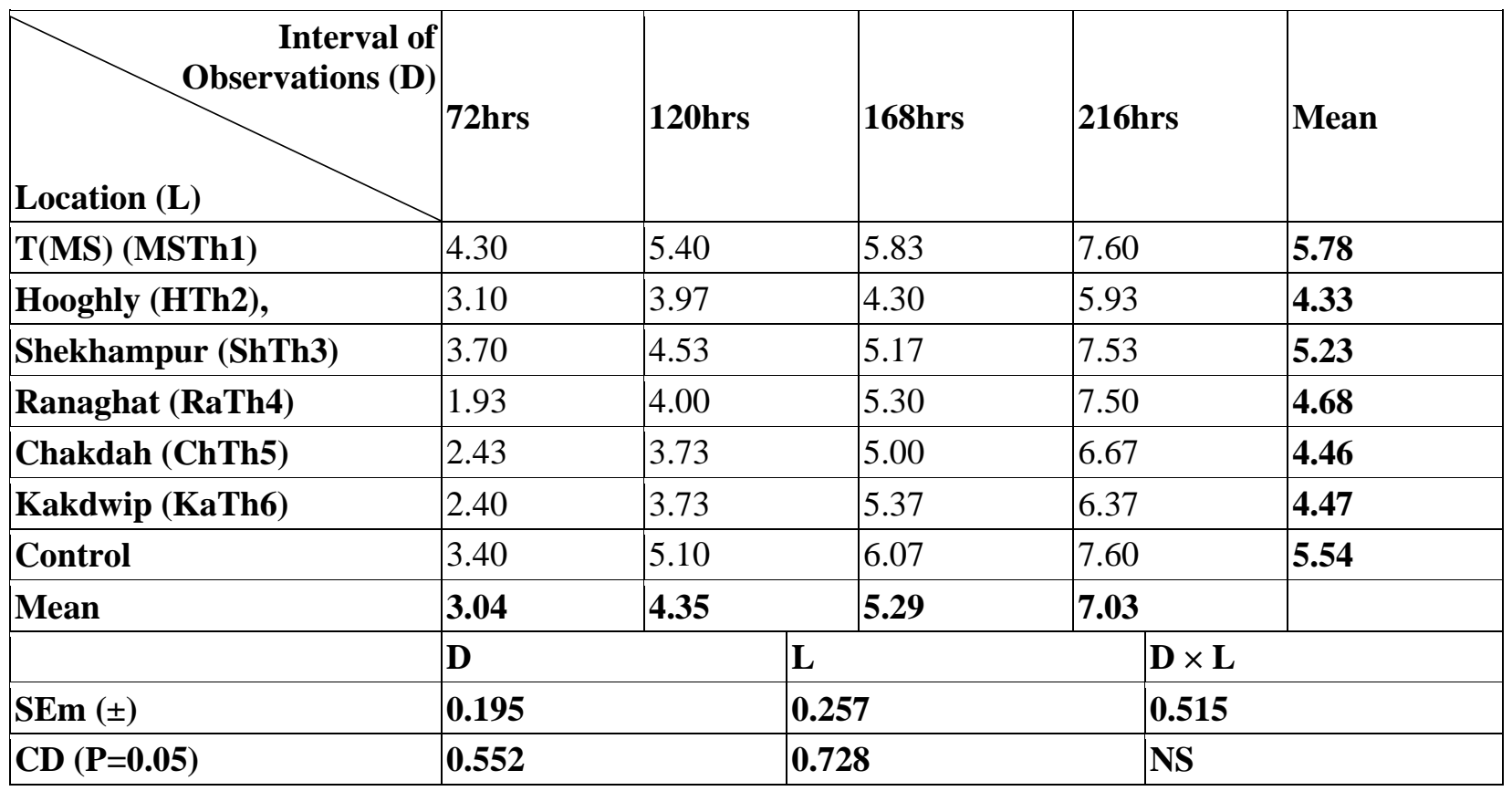


Table.2 Effect of Rhizobium on mycelia growth of Trichoderma (in cm)

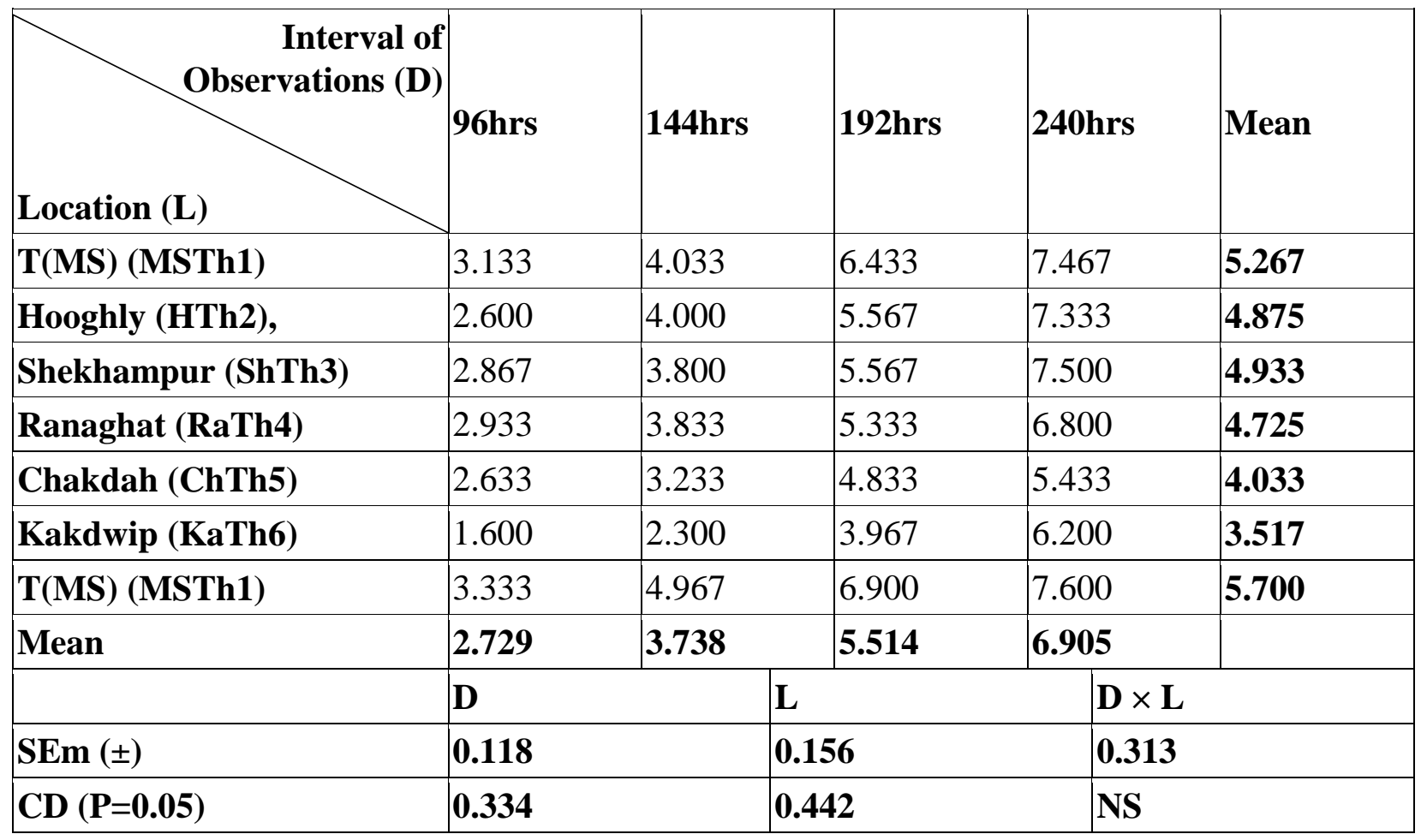

Table.3 In vitro colony count of Rhizobium in nos. over different isolates Trichoderma filtrate

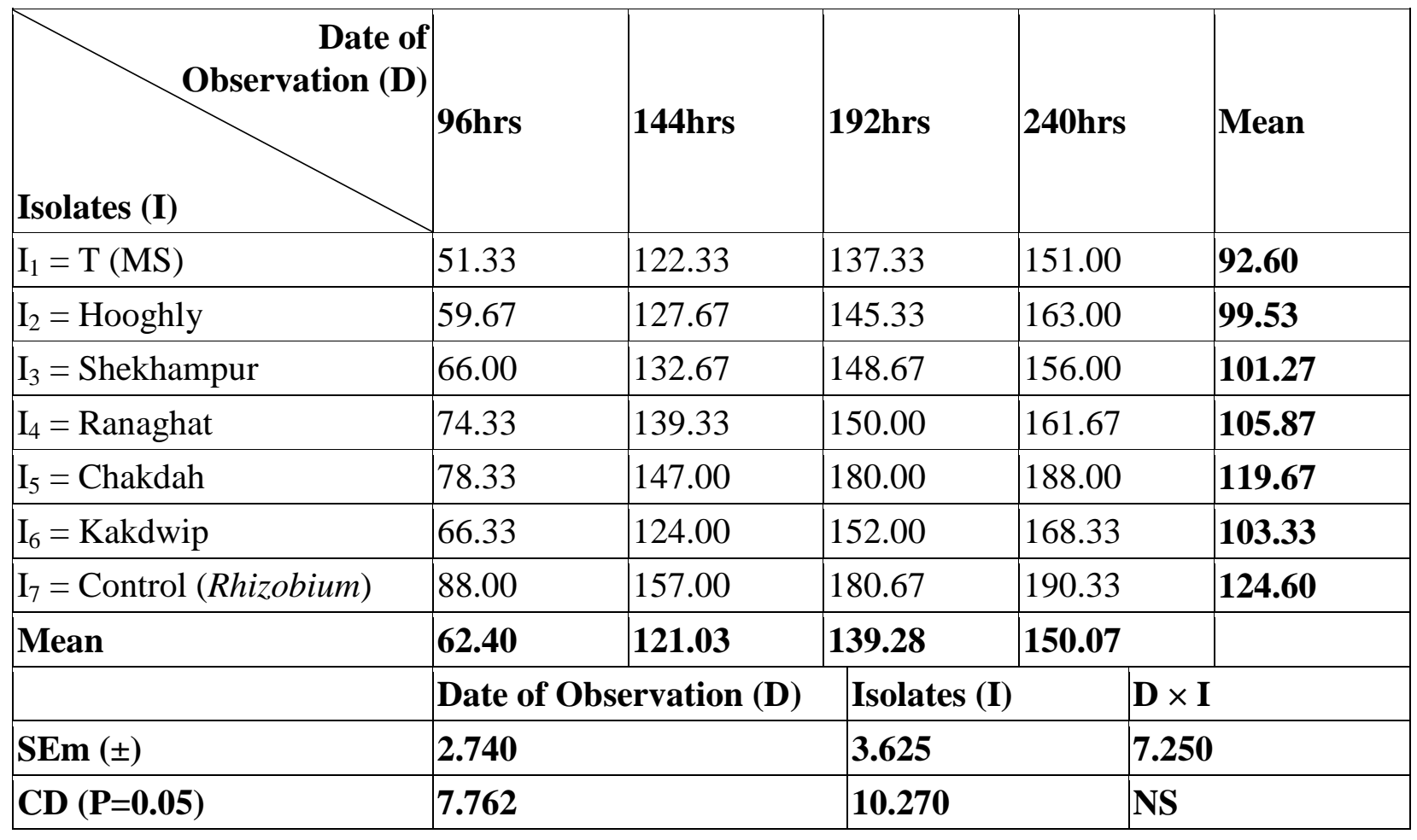


Table.4 Effect of interaction between Trichoderma and Rhizobium in their OD value as well as population

\begin{tabular}{|c|c|c|c|c|c|c|c|}
\hline Doses & OD VALUE & $\mathbf{A}$ & B & $\mathbf{C}$ & D & $\mathbf{E}$ & $\mathbf{F}$ \\
\hline \multirow[t]{2}{*}{$\mathrm{R}+\mathrm{T}(\mathrm{MS})$} & 0.590 & 9.23 & -21.19 & 95.33 & 43.18 & 5.66 & 46.11 \\
\hline & & $(17.68)$ & $(27.24)$ & & $(41.07)$ & & $(42.76)$ \\
\hline \multirow[t]{2}{*}{$\mathrm{R}+\mathrm{T}(\mathrm{S})$} & 0.280 & 51.28 & -22.18 & 101.66 & 42.27 & 5.33 & 35.64 \\
\hline & & $(45.73)$ & $(27.83)$ & & $(40.53)$ & & $(36.56)$ \\
\hline \multirow[t]{2}{*}{$\mathrm{R}+\mathrm{T}(\mathrm{H})$} & 0.510 & 21.53 & -26.95 & 99.33 & 41.34 & 2.66 & 57.93 \\
\hline & & $(27.64)$ & $(31.10)$ & & $(40.00)$ & & $(49.60)$ \\
\hline \multirow[t]{2}{*}{$\mathrm{R}+\mathrm{T}(\mathrm{R})$} & 0.513 & 21.02 & -49.60 & 95.66 & 42.93 & 2.33 & 67.85 \\
\hline & & $(27.24)$ & $(44.77)$ & & $(40.91)$ & & $(55.56)$ \\
\hline $\operatorname{SEm}( \pm)$ & 0.005 & 1.279 & 2.390 & 4.038 & 1.604 & 0.236 & 2.328 \\
\hline $\mathrm{CD}(\mathrm{P}=0.05)$ & 0.015 & 3.941 & 7.364 & NS & NS & 0.727 & 7.173 \\
\hline
\end{tabular}

$\mathrm{A}=\mathrm{OD}$ value over control Rhizobium (increase), $\mathrm{B}=\mathrm{OD}$ value over control Trichoderma (decrease), $\mathrm{C}=$ Population of Rhizobium as $1 \times 10^{8} \mathrm{cfu} / \mathrm{ml}, \mathrm{D}=$ Population of Rhizobium decrease over control, E=Population of Trichoderma as $1 \times 10^{8}$ spore $/ \mathrm{ml}, \mathrm{F}=$ Population of Trichoderma decrease over control, $\mathrm{R}+\mathrm{T}(\mathrm{MS})=$ Rhizobium + Trichoderma $($ Market sample), $\mathrm{R}+\mathrm{T}(\mathrm{S})=$ Rhizobium + Trichoderma $($ Shekhampur $), \mathrm{R}+\mathrm{T}(\mathrm{H})=$ Rhizobium + Trichoderma $($ Hoogly $), \mathrm{R}+\mathrm{T}(\mathrm{R})=$ Rhizobium+Trichoderma (Ranaghat)

Table.5 Effect of Rhizobium-Trichoderma interaction on the nodulation and root

\begin{tabular}{|c|c|c|c|c|c|c|c|c|}
\hline \multirow[t]{2}{*}{ Treatments } & \multicolumn{2}{|c|}{ Nodule } & \multicolumn{3}{|c|}{ Shoot } & \multicolumn{3}{|c|}{ Root } \\
\hline & $\begin{array}{c}\text { No. of } \\
\text { Nodule } \\
\text { (nos.) }\end{array}$ & \begin{tabular}{|c|} 
Fresh \\
Nodule \\
wt. (gm)
\end{tabular} & $\begin{array}{c}\text { Shoot } \\
\text { length } \\
(\mathrm{cm})\end{array}$ & $\begin{array}{c}\text { Fresh } \\
\text { hoot wt. } \\
\text { (gm) }\end{array}$ & $\begin{array}{c}\text { Dry shoot } \\
\text { wt. (gm) }\end{array}$ & $\begin{array}{l}\text { Root } \\
\text { length } \\
(\mathrm{cm})\end{array}$ & $\begin{array}{c}\text { Fresh } \\
\text { root wt. }\end{array}$ & $\begin{array}{c}\text { Dry } \\
\text { root wt. }\end{array}$ \\
\hline Rhizobium & 57.67 & 0.048 & 87.50 & 0.853 & 0.336 & 37.83 & 0.103 & 0.064 \\
\hline $\mathrm{T}(\mathrm{MS})$ & 44.67 & 0.039 & 81.37 & 0.699 & 0.315 & 41.70 & 0.114 & 0.039 \\
\hline $\mathrm{T}(\mathrm{S})$ & 43.67 & 0.038 & 83.33 & 0.812 & 0.302 & 43.83 & 0.110 & 0.051 \\
\hline $\mathrm{T}(\mathrm{H})$ & 42.00 & 0.037 & 84.07 & 0.817 & 0.284 & 40.49 & 0.102 & 0.017 \\
\hline $\mathrm{R}+\mathrm{T}(\mathrm{MS})$ & 76.33 & 0.068 & 79.67 & 0.864 & 0.333 & 41.13 & 0.081 & 0.042 \\
\hline $\mathrm{R}+\mathrm{T}(\mathrm{S})$ & 67.67 & 0.058 & 83.33 & 0.838 & 0.342 & 38.90 & 0.089 & 0.179 \\
\hline $\mathrm{R}+\mathrm{T}(\mathrm{H})$ & 61.00 & 0.049 & 78.20 & 0.829 & 0.289 & 40.00 & 0.101 & 0.034 \\
\hline Control & 34.00 & 0.035 & 79.87 & 0.825 & 0.253 & 39.93 & 0.090 & 0.038 \\
\hline $\operatorname{SEm}( \pm)$ & 3.219 & 0.003 & 3.54 & 0.032 & 0.017 & 2.490 & 0.007 & 0.048 \\
\hline $\begin{array}{l}\text { CD } \\
(P=0.05)\end{array}$ & 9.651 & 0.009 & NS & NS & 0.051 & NS & 0.021 & NS \\
\hline
\end{tabular}

$\mathrm{R}+\mathrm{T}(\mathrm{MS})=$ Rhizobium + Trichoderma $($ Market sample $), \mathrm{R}+\mathrm{T}(\mathrm{S})=$ Rhizobium + Trichoderma $($ Shekhampur $), \mathrm{R}+\mathrm{T}(\mathrm{H})=$ Rhizobium + Trichoderma $($ Hoogly), $\mathrm{R}+\mathrm{T}(\mathrm{R})=$ Rhizobium + Trichoderma $($ Ranaghat $)$ 
Fig.1 Dual culture technique showing interaction between 6 Trichoderma isolates and one Rhizobium

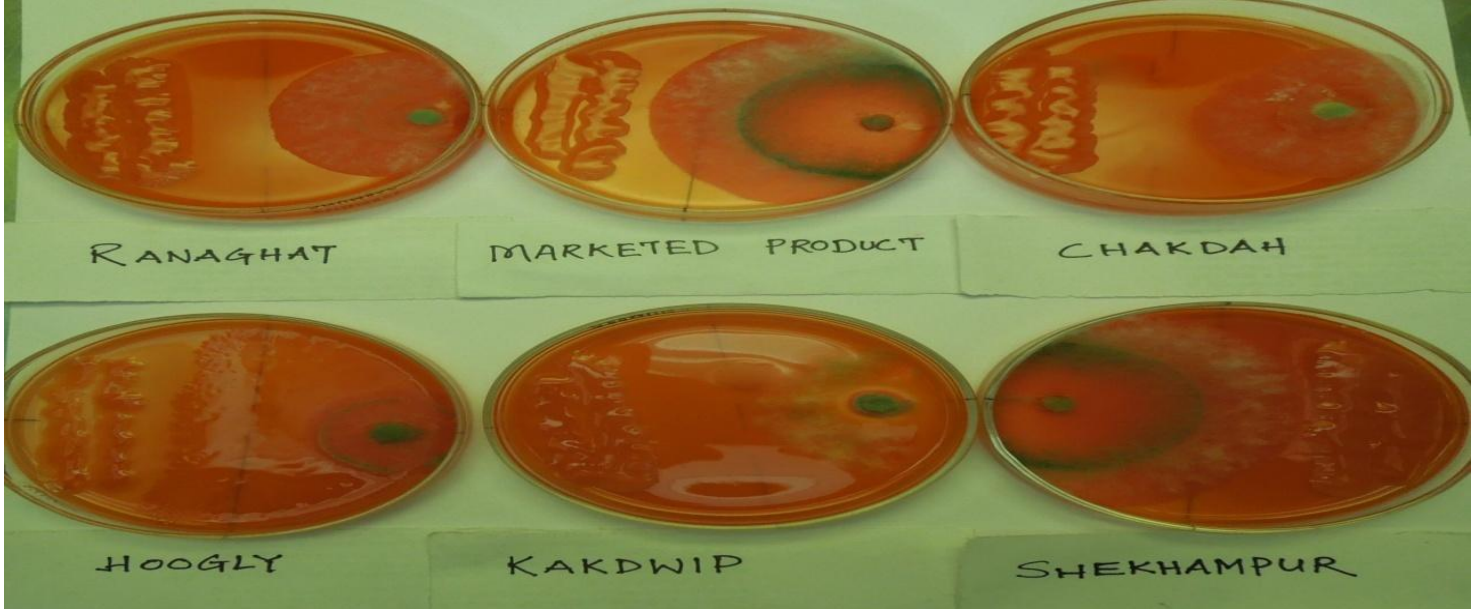

Fig.2 Effect of cultural filtrate of different Trichoderma isolates on the population of Rhizobium
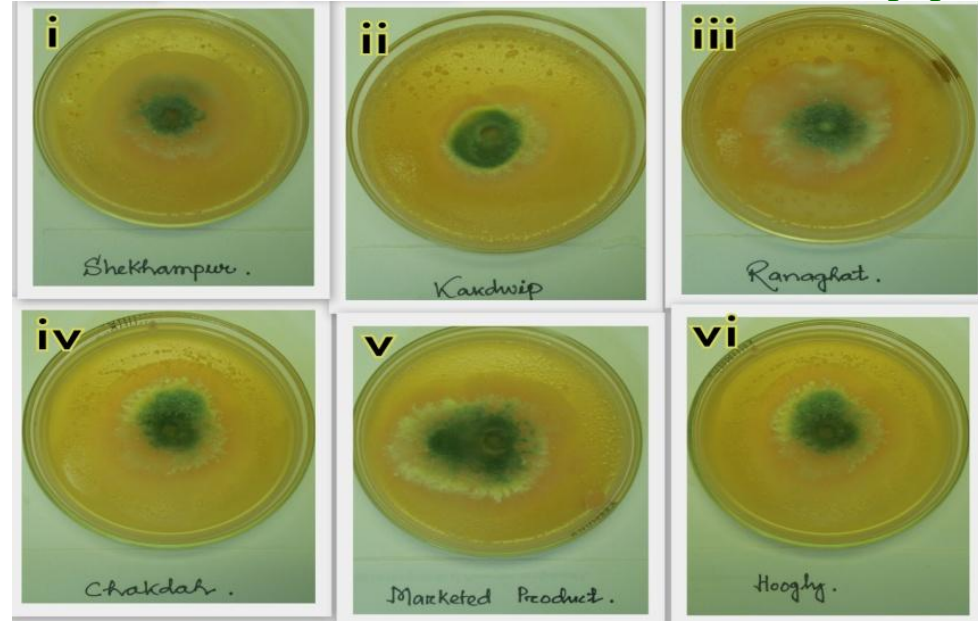

Fig.3 1(a) \& 1(b) are 30 days old lentil seedlings in pot in control and treated with Market Product respectively. 2(a) \& 2(b) are 30 days old lentil shoot in control and treatment condition (Market product) respectively. 3(a) \& 3(b) are root of 30 days old lentil in control and treatment Condition (Market product) respectively
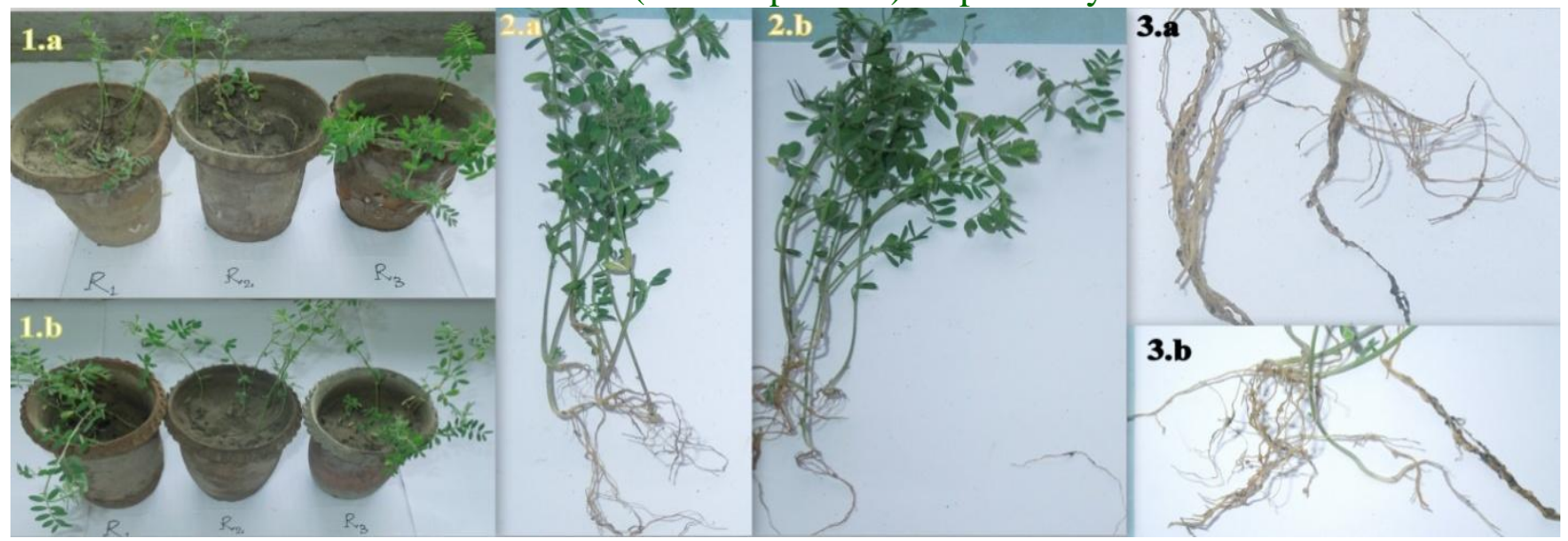
Population of different isolates Trichoderma were also decreased significantly over the Rhizobium and the maximum reduction was observed by Ranaghat isolate of Trichoderma $(67.85 \%)$ followed by Hoogly isolate $(57.93 \%)$ and minimum in Shekhampur isolate $(35.64 \%)$ followed by market sample of Trichoderma (46.11\%) and their differences were statistically significant. (Table 13)It was also observed that the individual growth of Trichoderma and Rhizobium was affected significantly when they were dual cultured in broth. The OD value as well as the population of Rhizobium showed no significant effect when cultured along with different isolated of Trichoderma though Sethi and Subha Rao (1968) observed a slight inhibitory effect of Rhizobium in the presence of certain strains of Trichoderma. But Jayaraj and Ramabadran (1999) indicated that mycelia mat of certain isolates of Trichoderma spp. strongly inhibit the growth of the Rhizobium. This inhibition may be due to the competition by the individual organism on the nutrient utilization and growth, antibiosis and lysis. Similarly, Jayaraj et al., (1994), observed a significant but slight inhibition of growth of 2 strains of Rhizobium by $T$. viride and $T$. harzianum in vitro.

\section{Rhizobium - Trichoderma interaction and their effect on Lentil in vivo}

A pot culture experiment were carried out using 3 isolates of Trichoderma i.e. Market sample (MSTh1), Shekhampur (ShTh3), Hoogly (HTh2) along with Rhizobium culture obtained from BCKV mass culture production were applied individually or in combination showed $100 \%$ germination of seeds in every treatment. Other growth factors were also collected the shoot length, root length, fresh and dry shoot weight, fresh and dry root weight, number of nodules and their fresh and dry weight. It was observed that shoot length, root length, fresh shoot weight and dry root weight showed no significant difference among themselves in increase their growth pattern. Whereas, number of nodules produced in the root, fresh nodule weight, dry nodule weight, dry shoot weight, fresh root weight were significantly differ in their growth behavior.

\section{Number of nodules}

Maximum number of nodules were produces on Market sample (MSTh1) of Trichoderma along with Rhizobium inoculated seed (76.33 nos.) followed by Trichoderma isolated from Shekhampur isolate (ShTh3) along with Rhizobium (67.67 nos.) though their difference were not statistically significant. The minimum number of nodules was observed in untreated control where no Rhizobium or no Trichoderma were added (34 numbers). It was also observed that combined application of Trichoderma and Rhizobium increase the number of nodule/6 plants in comparison to individual application of Trichoderma and Rhizobium (Table5).

\section{Fresh weight of nodules}

Similarly fresh weight of nodules was also increased in different treatment combination and their differences were statically significant. Maximum weight was observed in Rhizobium along with Market sample (MSTh1) combination $(0.068 \mathrm{gm})$ followed by combination with Rhizobium along with Trichoderma Shekhampur isolate (ShTh3) (0.058gm). Rhizobium along with Trichoderma Hoogly (0.049gm) and only Rhizobium (0.048gm), their difference were statistically significant except later two treatments. Minimum fresh nodule weight was observed only Trichoderma of Shekhampur (ShTh3), Market sample (MSTh1), Hoogly and untreated control though their differences were statically in significant. 


\section{Shoot length}

In case of shoot length, it was observed that, all the treatments combinations increase their shoot length in comparison to untreated control though their differences were not statistically significant. Here, individual application of Rhizobium and Trichoderma and their combined application showed no significant difference increase the shoot length. Similarly, fresh shoot weight was maximum in combined application of Rhizobium along with Market sample (MSTh1) (0.864) followed by single application of Rhizobium (0.853gm), combined application of Rhizobium along with Shekhampur isolate (ShTh3) (0.838gm) though their difference were not statistically significant were as minimum was observed Market sample (MSTh1) of Trichoderma only $(0.699 \mathrm{gm})$. Individual application of Rhizobium, Trichoderma and its combination showed differential dry shoot weight and their difference were statistically significant. Maximum dry shoot weight was found on Rhizobium and Trichoderma Shekhampur (ShTh3) isolate combination (0.342) followed by sole application of Rhizobium $0.33643 \mathrm{gm}$ combined application of Rhizobium and Trichoderma Market sample (MSTh1) isolate $(0.333 \mathrm{gm})$ and sole application of Trichoderma (Market sample (MSTh1) $(0.315 \mathrm{gm})$ and differences were not statistically significant (Table 5 and Fig. 3).

\section{Root length}

Root length was also different in different treatment sand maximum was observed sole application of Trichoderma Shekhampur (ShTh3) isolate $43.83 \mathrm{~cm}$ followed by combined application of Rhizobium and Trichoderma Market sample (MSTh1) isolate (41.13). Sole application of Trichoderma Market sample (MSTh1) 41.70 and they were statistically at par among themselves. It was observed that root length of different treatments showed no significant among themselves. Fresh root weights in different treatments were different and their differences were statistically significant. Among the treatments maximum weight was observed on sole application of Trichoderma Market sample (MSTh1) 0.114gm followed by Trichoderma, Shekhampur (ShTh3), Trichoderma Hoogly (HTh2), Rhizobium and their differences were not statistically significant Dry root weight was maximum on combined application of Rhizobium, Trichoderma and Trichoderma Shekhampur (ShTh3) isolate $0.17947 \mathrm{gm}$ followed by sole application of Rhizobium $0.06487 \mathrm{gm}$ sole application of Trichoderma Shekampur (ShTh3) 0.05180gm though their differences were not statistically significant (Table 5 and Fig. 3).

The pot culture experiment on Lentil seed (Var.- B-177) treated with different Trichoderma isolates $\left(1 \times 10^{8}\right.$ spore suspension) and Rhizobium cell suspension $\left(1 \times 10^{8} \mathrm{cfu} / \mathrm{ml}\right)$ were sown on earthen pot under greenhouse condition to find out the different growth behavior of lentil plant due to combined application of Rhizobium and Trichoderma and its was observed that different growth behavior like no. of nodule, fresh nodule weight, dry root weight, dry shoot weight, fresh root weight are significantly different among themselves, in increase or decrease of growth behaviors' when they were applied individually or in combination. Whereas shoot length, fresh shoot weight, root length and dry root weight showed no significant difference among the different treatment combination. Here, it was observed that the combination of Rhizobium and Shekhampur and Market sample isolate of Trichoderma (MSTh1) increased the number of root nodules, fresh nodules, dry nodule weight, dry nodule weight, dry shoot weight significantly in comparison to control 
and sole application of Rhizobium. Whereas, the result contradict with the result of Jayaraj and Ramabadran (1999) that Rhizobium alone and Rhizobium Trichoderma mixture were statistically at par on increase the number of nodules. Though, biomass yield increased slightly when Rhizobium and Trichoderma were applied in combination. Similar type of result was also observed by Sridhar et al., (1993) that slight increase in nodulation of Urd bean following combined inoculation of Rhizobium with Bacillus subtilis.

\section{References}

Badarneh, D. M. D. (1995). Magnitude of nitrogen fixation by lentil at different rates of phosphorous using $15 \mathrm{~N}$ technique. Journal of Agronomy and Crop Science. 175: 7-14.

Deshwal, V. K., Dubey, R.C. and Maheshwari, D.K. (2003). Isolation of plant growth-promoting strains of Brady Rhizobium (Arachis) sp. with biocontrol potential against Macrophomina phaseolina causing charcoal rot of peanut. Current Science, 84: 443-448

Dorosinsky, L.M., Kadyrov, A.A. (1975). Effect of inoculation of nitrogen fixation by chickpea, its crop and content of protein. Microbiologiya 44, 1103-1106.

Elad, Y. and Chet, I. (1983). Improved selective media for isolation of Trichoderma spp. and Fusarium spp. Phytoparasitica 11: 55-58.

Frederick, M., Cho, S., Sarker, A., McPhee, K. and Coyne, C. (2006) Application of biotechnology in breeding lentil for resistance to biotic and abiotic stress. Euphytica 147(1-2): 149-165.

Frederick, M., Cho, S., Sarker, A., McPhee, K. and Coyne, C. (2006) Application of biotechnology in breeding lentil for resistance to biotic and abiotic stress. Euphytica 147(1-2): 149-165.
Harris, G.E. and Sommers, L.E. (1968). Plate dilution technique for assay of microbial ecology. Applied Microbiology, 16: 330-334.

Herandez, L.G., Hill, G.S., (1983). Effect of plant population and inoculation on yield and yield components of chickpea (Cicer arietinum). Proceedings of Agronomical Society of New Zealand. 13, 75-79.

Islam, M.D.T., Dembele, D.P. and Keller, E.R.J. (2005). Influence of explant, temperature and different culture vessels on in vitro culture for germplasm maintenance of four mint accessions. Plant Cell, Tissue and Organ Culture 81:123-130.

Jayaraj,J., and Ramabadran, R. (1999) Rhizobium - Trichoderma interaction in vitro and in vivo. Indian Phytopathology, 52(2): 190-192

Kumar, R.N., and Mukerji, K.G. (1996). Integrated disease management future perspectives. In: Mukerji, K.G., Mathur, B., Chamola, B.P., Chitralekha, C. (Eds.), Advances in Botany, New Delhi, pp. 335-347.

Medina-martinez,E., Rodriguez-alvarez,O., and Hernandez-valdes, A. (2002). Compatibility of Azototobacter sp. and Trichoderma sp. with different pesticides. Centro-agricola. 8: 34-38.

Mukhopadhyay, A.N. and Kaur, N.P. (1990). Biological control of chickpea wilt complex by Trichoderma harzianum. Proc. Third International Conference of Plant Protection in Tropics, Malaysia, March 20-23.

O'Hara, G., Yates, R. and J, Howieson. (2002). Selection of strains of root nodule bacteria to improve inoculants performance and increase legume productivity in stress full environments. In: D. Herridge, (eds) inoculants and Nitrogen fixation of legumes in 
Vietnam. ACIAR Proceedings 109: 7580.

Papavizas, G.C. (1985), Trichoderma and Gliocladium: biology, ecology, and potential for biocontrol. Annual Review of Phytopathology, 23: 23-54

Patil, R.N., Shinde, P.A., (1980). Studies on nodulation pattern in gram (Cicer arietinum L.). Journal of Maharashtra Agricultural. University. 5, 211-213.

Rangaswami, G. (1958). Science and Culture, 24:85.

Rifai, M.A. (1969). A revision of the genus Trichoderma. Mycology Paper 116: 1116.

Rifai, M.A., and Webster, J. (1966). Culture studies of Hypocrea and Trichoderma aureoviridis and $\mathrm{H}$. rufa $\mathrm{f}$. sterilis. Transaction of British Mycological Society. 49:289-296

Rudresh, D.L., Shivprakash, M.K. and Prasad, R.D. (2005). Effect of Combined Application of Rhizobium, Phosphate Solubilizing Bacterium and Trichoderma spp. on growth, nutrient uptake and yield of chick pea. Applied Soil Ecology, 28(2): 139-146

Sarker, A., Kumar, S. (2011). Lentils in production and food systems in West Asia and Africa. International Center for Agricultural Research in the Dry
Areas (ICARDA), Aleppo, Syria. Grain Legumes 57: 46-48.

Schulze, J., Temple. G. S., Beschow. H and Vance. C. P. (2006). Nitrogen fixation by white lupin under phosphorus deficiency. Annual. Botany. 98: 731740.

Sethi, R.P. and Subha Rao, N.S. (1968). Journal of general applied microbiology. 14:325-327

Sridhar, R., Ramakrishnan, G., Dinakaran, D. and Jeyarajan, R. (1993). Journal of Biological Control, 7: 51-51

Verma, M., Brar, S.K., Tyagi, R.D., Surampalli, R.Y. and Valero, J.R. (2007). Antagonistic fungi,

Trichoderma spp.: Panoply of biological control. Biochemical Engineering Journal, 37:1-20

Vincent, J.M. (1947). Distortion of fungal hyphae in the presence of certain inhibitors. Nature. 159:850-850.

Whipps, J.M and Lumsden, R.D. (2001). Commercial use of fungi as plant disease biological agents: status and prospects. In: T. Butt, C. Jackson, N. Magan (Eds), and Fungal Biocontrol agents: progress, problems and potential, pp. 9-22.

\section{How to cite this article:}

Tanusree Das, Sunita Mahapatra and Srikanta Das. 2017. In vitro Compatibility Study between the Rhizobium and Native Trichoderma Isolates from Lentil Rhizospheric Soil. Int.J.Curr.Microbiol.App.Sci. 6(8): 1757-1769. doi: https://doi.org/10.20546/ijcmas.2017.608.208 